\title{
Comparing Students' Perceptions and Their Writing Performance on Collaborative writing: A Case Study
}

\author{
Fangyuan $\mathrm{Du}^{1}$ \\ ${ }^{1}$ College of Foreign Languages and Literature, Fudan University, Shanghai, China \\ Correspondence: Fangyuan Du, College of Foreign Languages and Literature, Fudan University, Shanghai, \\ China.
}

\author{
Received: October 13, 2018 Accepted: November 16, 2018 Online Published: November 20, 2018 \\ doi: 10.5539/elt.v11n12p131 URL: https://doi.org/10.5539/elt.v11n12p131
}

\begin{abstract}
One important strand of research in collaborative writing has been the learners' attitudes and perceptions toward collaborative writing. This study sets out to compare three pairs of students' perceptions and their actual collaborative writing practices. Multiple sources of data were collected. Students' semi-interviews were audio recorded, transcribed and analyzed for their perceptions. Their collaborative writing tasks are also recorded and analyzed for quantity, type and resolution of language related episodes (LREs). The study further examined the collaborative texts using both quantitative and qualitative measures for students' language improvement. Our finding suggest that most participants expressed positive attitudes towards collaborative writing but only half of them were aware of language improvement. An analysis of pairs' discussion revealed that participants were overly concerned with vocabulary and all LREs were successfully resolved. The quantitative and qualitative analysis of collaborative texts demonstrated that two pairs received considerable language improvements in terms of lexical diversity, syntactic complexity, fluency and text quality. These findings can be used to encourage students to reflect on their own perceptions and practices in collaborative writing tasks.
\end{abstract}

Keywords: second language writing, collaborative writing, learners' perceptions, writing performance

\section{Introduction}

Collaborative writing is typically defined as the joint production of a text or the coauthoring of a text by two or more writers (Storch, 2011). Recent years have witnessed a significant growth of research on collaborative writing in L2 classroom (Li \& Zhu, 2017; Mozaffari, 2017; Storch, 2013; Wu, 2015; Zhang, 2018). The use of collaborative writing tasks is supported by cognitive and sociocultural theories of L2 learning. From the cognitive perspective, Long's (1996) interaction hypothesis suggests that negotiating for meaning and form increases the learning opportunities and facilitates L2 learning. On the other hand, the sociocultural perspective of learning, originally based on Vygotsky (1978), emphasized that language learning was inherently a socially mediated process. Learners construct knowledge in social interaction with experts or more capable peers.

\section{Literature Review}

Over the last 10 years, the study of collaborative writing in second language (L2) classrooms has attracted much attention. A number of research has shown that learning gains obtained from collaborative writing in the classroom (Elola \& Oskoz, 2010; Fernandez Dobao, 2012; Wu, 2015). Two strands can be discerned in the body of research. The first strand comprises studies that have investigated the outcomes of collaborative writing tasks. Comparing texts produced by pairs with texts produced by individuals, Wigglesworth and Storch (2009) found that texts produced by pairs were more accurate than the texts produced individually. Fernandez Dobao (2012) went further to compare the same writing task by groups of four learners, pairs and individual learners. The analysis of written texts revealed that production of groups was more accurate not only than those written individually, but also than those written in pairs. The second strand includes studies that have focused on L2 learners' perspectives about collaborative writing. In a long-term study (Shehadeh, 2011) investigating two group students' perceptions of collaborative writing, most students in experiment group found the experience enjoyable and the partner add extra ability and strength to their capabilities. In Fernandez Dobao and Blum's (2013) study, students' reactions to one collaborative writing task were overall positive although a third of them could not see a positive impact on improvement of grammar or vocabulary knowledge. Therefore, more research is needed about the perceptions of learners to collaborative writing in order to gain a better understanding of learners' 
observed behavior and language learning outcomes of collaborative writing tasks.

However, existing research has focused on language learning opportunities in collaboration, but no research has compared the students' perceptions regarding language use/improvement with the actual collaborative tasks they complete. To date, no research has been done in L2 research to compare students' perceptions, their observed behavior and their writing outcomes of collaborative writing tasks. This study aims to take a close look at the interactions between learners' perceptions about their language improvement and their collaborative writing products. Specifically, they study addressed the following questions:

1) What are the students' perceptions about collaborative writing tasks?

2) What are the students' actual collaborative writing practices?

3) What is the relationship between students' perceptions and their actual collaborative writing practices?

\section{Method}

\subsection{Participants}

Three dyads were selected from a pool of 69 students who enrolled in a semester-long essay-writing course. They were from a variety of majors and had studied English as a foreign language for at least seven years. The majority of them were freshmen or sophomores in their early twenties. Three dyads were selected based on their L2 writing proficiency and their participation in the interviews. The proficiency level of first dyad was intermediate and upper intermediate, while that of the second and third dyad were upper intermediate and lower intermediate as well as intermediate and intermediate.

\subsection{Procedures}

The participants were asked to finish four collaborative writing tasks during weeks five, eight, eleven and fourteen of a 16-week EFL writing course. Specifically, they need to respond to a writing task in pairs and write one paragraph collaboratively in 20 minutes. The format and type of four writing tasks were the same, consisting of mainly argumentative writing (a controversial topic). In week one, students were informed about the class arrangements and required to find a partner. All the discussions in the collaborative writing tasks were audiotaped. For the purpose of this paper, three pairs were interviewed at the end of the semester in order to elicit participants' perceptions.

\subsection{Data Analysis}

Following Swain and Lapkin (1998), transcriptions of students' collaborative writing tasks were analyzed for language related episodes (LREs). LREs are usually defined as the dialogue in which students explicitly pay attention to language, question their language use or correct themselves or others. Based on their focus on grammar or vocabulary, LREs are classified as either form-focused or lexis-focused. According to their outcome, LREs are also divided into correctly resolved, unresolved or incorrectly resolved. (Storch, 2013)

To demonstrate the types and outcome of LREs, three examples from the data are given below. Excerpt 1 is a lexis-focused LRE dealing with word choice. In this case, speaker A looked for the correct translation of 延伸. Speaker B gave the word "Board" but speaker did not accept it. Instead, speaker A came up with another word "extending" and speaker B agreed. Therefore, this LRE was correctly resolved.

\section{Excerpt 1: Lexis-focused LRE/Correctly resolved LRE}

Speaker A: Yes, yes. For example, let me check it on the Internet for 延伸.

Speaker B: Board. I think board is OK. BOARD

Speaker A: extending, extending.

Speaker B: em. Extend. This is OK, too.

Speaker A: extension. This strengthen extension of our ability.

Excerpt 2 is also a lexis-focused LRE with word choice. Speaker A came up with the phrase "big data time" but speaker B changed the word "data" as "digital". Speaker B accepted it and wrote down the wrong expression "big digital time". Therefore, this LRE was incorrectly resolved.

Excerpt 2: Lexis-focused LRE/Incorrectly resolved LRE

Speaker A: so write, just write with the help of technology students can learn more information.. data..

Speaker B: Nowadays is a...不不不...the world is a...step to a..

Speaker A: big data time. 
Speaker B: big data time? digital.

Speaker A: oh, yeah, digital, big digital time.

Excerpt 3 is a form-focused LRE. Speaker B first gave two suggestions but speaker A ignored. Then speaker B suggested making a contrast but speaker A resisted it by giving a reason. Therefore, this LRE was unresolved.

Excerpt 3: Form-focused LRE/ unresolved LRE

Speaker B: We can just say there is a hypothetic

Speaker B: En...we can just say for example

Speaker A: To write a paper

Speaker A: A few decades ago, the only access to getting relevant information for writing a paper is to search in the library. It costs a lot of time. In contrast, with Internet and some digital devices.

Speaker B: So we can just make a contrast between the former and the latter.

Speaker A: The latter? But before 'the latter' we need 'the former'. We did not write a 'former'. We just say...it is convenient to search it on the internet. In addition, ...

The in-class collaborative writing texts were analyzed for lexical diversity, syntactic complexity, fluency, accuracy and text quality. We used two lexical diversity measures obtained from the computational tool Lexical Complexity Analyzer (Lu, 2012): number of different words (NDW), corrected type-token ratio (CTTR). NDW is a straightforward measure of lexical variation. While dependent on the length of the language sample, it is still useful for language samples in this study (around 100 words). CTTR refers to corrected type-token ratio. Type-token ratio (TTR), the ratio of the number of word types to the number of words in a text, is widely used in second language acquisition. Although TTR has been criticized for the decrease of ratio as the size of the sample increases, CTTR has been proved to validly predict lexical diversity ( $\mathrm{Lu}, 2012)$.

For syntactic complexity and fluency, we used the L2 Syntactic Complexity Analyzer (Lu, 2010), which automatically analyzes syntactic measures of L2 writing. Syntactic complexity was measured in three ways: mean length of clause, mean length of T-unit, and clauses per T-unit; fluency was measured as average number of words, T-units and clauses per text. Most studies regarded a clause as a structure with a subject and a finite verb, including independent, adjective, adverbial, and nominal clause ( $\mathrm{Lu}, 2011)$. T-unit is consistently defined as "one main clause plus any subordinate clause or non-clausal structure that is attached to or embedded in it" (Hunt, 1970, P.4). Following previous research (Fernandez Dobao, 2012; Wigglesworth \& Storch, 2009), accuracy was assessed using the number of error-free T-units and error-free clauses.

A text quality criteria containing three five-point band descriptors (i.e. content, organization, language) was developed. The band descriptors for content, organization and language were adapted from IELTS's writing task 2 assessment criteria. Furthermore, interviews of 12 students were transcribed, coded and analyzed.

\section{Results}

\subsection{What Are the Students' Perceptions About Collaborative Writing Tasks?}

This section reports on participants' perceptions. These perceptions were organized into two themes. Table 1 outlines their general attitudes and perceived writing improvement. Overall, participants expressed positive attitudes towards collaborative writing tasks, with only one showed unfavorable attitude. However, three participants were not aware of any writing improvement, content, grammar or vocabulary in particular. Two of them were in one pair with same proficiency level and another one was an upper intermediate participant with a lower intermediate partner.

Specifically, Jiao and Ma thought collaborative writing improved their sentence structure and helped them write longer in a limited time, respectively. $\mathrm{Wu}$, who was the only one showing negative attitude in this study, complained that his partner could not express himself very clearly in English, which prevented them from sharing ideas with each other. In contrast, his partner Chen held a positive attitude and reported it helped pool ideas together but not learn grammar or vocabulary. He said, "learning vocabulary is mainly from reading out of classroom instead of writing." The last pair, Yang and Yu, both in the same proficiency level, although expressed positive attitudes, did not gain writing improvement in terms of grammar or vocabulary. 
Table 1. Students' perceptions about collaborative writing tasks

\begin{tabular}{llll}
\hline Name & Proficiency level & General attitudes & Perceived writing improvement \\
\hline Jiao & Intermediate & Positive & Grammar, particularly sentence structure \\
Ma & Upper intermediate & Positive & Writing longer \\
Wu & Upper intermediate & Negative & No \\
Chen & Lower intermediate & Positive & Content, not grammar or vocabulary \\
Yang & Intermediate & Positive & No \\
Yu & Intermediate & Positive & No \\
\hline
\end{tabular}

\subsection{What Are the Students' Actual Collaborative Writing Practices?}

An analysis of pairs' discussion revealed that participants were overly concerned with vocabulary rather than grammar and all of LREs were correctly resolved (see Table 2). It was difficult to establish whether the amount of time spend on language correlated to grammar accuracy and lexical diversity. For example, Yang and Yu, who achieved lowest accuracy and complexity scores, produced most LREs among three pairs.

Table 2. Number, type and outcome of LREs

\begin{tabular}{lllllll}
\hline Name & $\begin{array}{l}\text { Number of form-focused } \\
\text { LREs }\end{array}$ & $\begin{array}{l}\text { Number } \\
\text { LREs }\end{array}$ & of & lexis-focused & $\begin{array}{l}\text { Number of correctly resolved } \\
\text { LREs }\end{array}$ \\
\cline { 2 - 7 } & Time 1 & Time 4 & Time 1 & Time 4 & Time 1 & Time 4 \\
Jiao \& Ma & 0 & 0 & 2 & 0 & 2 & 0 \\
Wu \& Chen & 0 & 0 & 2 & 0 & 2 & 0 \\
Yang \& Yu & 1 & 0 & 1 & 2 & 2 & 2 \\
\hline
\end{tabular}

Table 3 summarizes the results of the quantitative and qualitative analysis for the three pairs. The descriptive statistics revealed that lexical diversity increased from the Time 1 to Time 4 . In terms of sentence complexity, three pairs tended to write more complex sentences, as measured by mean length of T-unit, mean length of clause, and clauses per T-unit. The mean length of T-unit and clause was much longer in fourth time for two pairs, Jiao and Ma and Yang and Yu. The T-units in the texts produced by Jiao and Mao were not only longer but also contained on average almost two clauses (1.17). However, the results of the above three measures were quite the opposite for $\mathrm{Wu}$ and Chen, even though they wrote longer texts. For fluency, three pairs tended to compose longer texts in fourth collaborative writing task (at the end of the semester) compared with the first time, even though we did not see much changes in T-units and clauses for two pairs, Jiao and Ma, Yang and Yu. In terms of accuracy, texts produced in fourth time seemed more or less the same with those produced in first time, with $\mathrm{Wu}$ and Chen wrote $100 \%$ correct sentences for both times and the other pairs wrote one clause wrong for each time. Most of these errors related to omission of sentence elements in complex sentence. Additionally, the qualitative scores for all three pairs were improved in total scores in fourth time. What is interesting to note is that each pair received higher score either in content or organization or both, but not in language.

Table 3. Quantitative and qualitative analysis of collaborative writing texts

\begin{tabular}{lllllll}
\hline \multirow{2}{*}{ Measures } & \multicolumn{2}{c}{ Jiao \& Ma } & \multicolumn{2}{c}{ Wu \& Chen } & \multicolumn{2}{c}{ Yang \& Yu } \\
& Time 1 & Time 4 & Time 1 & Time 4 & Time 1 & Time 4 \\
\hline Lexical diversity & & & & & & \\
Number of different words & 57 & 81 & 65 & 81 & 52 & 60 \\
$\begin{array}{l}\text { Corrected type-token ratio } \\
\text { Syntactic complexity }\end{array}$ & 4.35 & 4.91 & 4.9 & 5.36 & 4.46 & 4.74 \\
Mean length of T-unit & 12 & 19.43 & 14.67 & 11.4 & 11 & 16 \\
Mean length of clause & 7.64 & 11.33 & 7.33 & 8.14 & 8.25 & 10 \\
\hline
\end{tabular}




\begin{tabular}{lllllll}
\hline Clauses per T-unit & 1.57 & 1.71 & 2 & 1.4 & 1.33 & 1.6 \\
Fluency & & & & & & \\
Word count & 84 & 136 & 88 & 114 & 66 & 80 \\
T-units & 7 & 7 & 6 & 10 & 6 & 5 \\
Clauses & 11 & 12 & 12 & 14 & 8 & 8 \\
Accuracy & 7 & 6 & 6 & 10 & 5 & 4 \\
Error free T-units & 11 & 11 & 12 & 14 & 7 & 7 \\
Error free clauses & 7 & 7.8 & 8 & 8.7 & 6 & 6.3 \\
Text quality & 7 & 8 & 8 & 9 & 6 & 6 \\
Total score & 7 & 8 & 8 & 9 & 6 & 7 \\
Content & 7 & 7.5 & 8 & 8 & 6 & 6 \\
Organization & 7 & & & & \\
Language & 7 & & & & & \\
\hline
\end{tabular}

\subsection{What Is the Relationship Between Students' Perceptions and Their Actual Collaborative Writing Practices?}

Table 4 outlines the comparison between students' perceptions about collaborative writing and their actual collaborative writing performance. The perceptions are categorized by general attitudes and perceived writing improvements. Each perception is compared to whether it was observed in the actual writing performance or not.

Table 4. Participants' perceived writing improvement and their actual performances

\begin{tabular}{lllll}
\hline Name & Perceived writing improvements & \multicolumn{2}{l}{ Collaborative writing texts } \\
\cline { 3 - 5 } & & Content & Sentence structure & Vocabulary \\
Jiao & Grammar, particularly sentence structure & 0 & $\sqrt{ }$ & $\times$ \\
Ma & Writing longer & $\sqrt{ }$ & 0 & $\times$ \\
Wu & No & $\times$ & $\sqrt{ }$ & $\sqrt{ }$ \\
Chen & Content, not grammar or vocabulary & $\sqrt{ }$ & $\sqrt{ }$ & $\sqrt{ }$ \\
Yang & No & 0 & $\times$ & $\times$ \\
Yu & No & 0 & $\times$ & $\times$ \\
\hline
\end{tabular}

Notes: $\sqrt{ }=$ observed $; \times=$ not observed; $\mathrm{o}=$ not mentioned.

As Table 4 indicated, although some of perceived writing improvements converged with their actual writing texts, there were also a lot of elements in their actual writings that tended to diverge from their own thinking. For Yang and $\mathrm{Yu}$, they both stated no vocabulary or grammar improvement in their collaborative writing texts. However, quantitative and qualitative analysis of their writing proved that they wrote more different words and longer T-units and clauses and also gained improvement in organization. On the contrary, for $\mathrm{Wu}$ and Chen, there was mainly convergence with their collaborative writing texts. For instance, they both felt the collaborative writing experience did not enhance their writing ability and it was observed in their writing texts. For Jiao \& Ma, while their perception of sentence structure and content corresponded to their collaborative writing texts respectively, they did not realize their lexical improvement from Time 1 to Time 4.

\section{Discussions}

Overall, the findings suggest that three pairs' perceived writing improvements partly converge with their actual writing texts. For $\mathrm{Wu}$ and $\mathrm{Chen}$, an upper intermediate student and a lower intermediate student, though their collaborative writing texts corresponded to their perceptions, the reasons may not be the same. As an upper intermediate student, $\mathrm{Wu}$ demonstrates a negative attitude toward the collaborative writing and may not learn grammar or vocabulary from his partner because of the proficiency level. L2 proficiency grouping has long received most research attention (Storch, 2011). Some research finds that learners may not regard pair work as a useful learning opportunity because their peers have a lower L2 proficiency (Storch, 2013). It could also be 
accounted for Vygotsky's (1978) theory of learners' constructing knowledge with more capable individuals. By contrast, his partner, Chen, a lower intermediate student, though showing a positive attitude toward the collaborative writing task, may not learn grammar or vocabulary due to his participation in the task. From their actual writing texts with high scores, it seems likely that they were largely written by $\mathrm{Wu}$, instead of Chen. In the interview, he also mentioned prioritizing meaning over form during the task. That's why Chen did not feel improvement in his own writing. Nevertheless, Chen's perception about content improvement through collaborative writing can be proved in their actual writing texts. He emphasized sharing ideas with the partner helped their writing in the interview. Learning from each other's ideas is an advantage frequently cited in the studies (Storch, 2005; Shehadeh, 2011; Wigglesworth \& Storch, 2012; Fernandez Dobao et al., 2013).

Jiao \& Ma is the most enthusiastic dyad among the three pairs. They both thought their writing abilities were largely enhanced and they did. A possible reason for Jiao's improvement in sentence structure could be related to her discussion with her partner, who is an upper intermediate learner. Jiao reported in the interview that her partner was good at coherence and cohesion and she learned a lot from her. This finding is consistent with previous study reporting that "engage them in cognitive processes that might be a source of L2 learning" (Shehadeh, 2011).

While some of participants' perceived writing improvements corresponded to the collaborative writing texts, some did not. For instance, though neither Yang nor Yu reported gaining vocabulary or grammar improvement through collaborative writing activities, their writing texts demonstrated development in syntactic complexity and lexical diversity. Possible reasons for divergence may be related to task types. Unlike other research using graphic/visual prompt or descriptive writing (Stroch 2005; Shehadeh 2011; Fernandez Dobao et al. 2013), this study adopted a different task type - argumentative writing. By using a controversial topic as a writing prompt, some students may focus more on the content instead of language. Yang also expressed the concern over the disagreement on the topic when they wrote collaboratively. It should be noted that Jiao \& Ma also did not feel lexical development in their collaborative writing. The reason may be related to their belief that writing is not a tool for learning grammar or vocabulary. This is in line with the conclusion reached by Fernandez Dobao et al. (2013) that students did not think they could learn vocabulary or grammar while working with partners of the same or lower proficiency level.

From a pedagogical perspective, the difficult task facing writing teachers is how to group students based on their different proficiency levels, but at the same time ensure their language learning opportunities. Collaborative writing tasks combine a focus on language form and meaning (Storch, 2013). Besides the meaningful communications students have already enjoyed, teachers need to enhance students' motivation and engagement and to raise students' awareness of the potential and actual benefits of collaborative writing tasks in the EFL classroom.

\section{Conclusion}

The purpose of this case study was to examine the relationship between three pairs of EFL students' perceptions and their actual writing performance to collaborative writing tasks. Overall, the study reveals that their writing improvements were partly articulated in their perceptions. Further, some of the syntactic and lexical development in collaborative writing texts diverged from students' own thinking possibly because task types and students' proficiency levels. Therefore, language teachers need to encourage students to reflect on their perceptions and writing texts because collaborative writing provides learners with opportunities to learn through a discussion of the language they are using (Wigglesworth et al., 2012).

Our study has a number of limitations that should be followed up by further research. First, we cannot make general claims about collaborative writing tasks based on the three cases we have analyzed, though we believe they reflected issues highlighted in previous research. Future research will need to compare more students' reactions to different types of writing tasks. In addition, the scope of the present study could also be extended to the development of learners' perceptions over time.

\section{References}

Elola, I., \& Oskoz, A. (2010). Collaborative writing: Fostering foreign language and writing convention development. Language Learning \& Technology, 14(3), 51-71.

Fernandez Dobao, A. (2012). Collaborative writing tasks in the L2 classroom: Comparing group, pair and individual work. Journal of Second Language Writing, 21(1), 40-58. https://doi.org/10.1016/j.jslw.2011. 12.002

Fernandez Dobao, A., \& Blum, A. (2013). Collaborative writing in pairs and small groups: Learners' attitudes 
and perceptions. System, 41(2), 365-78. https://doi.org/10.1016/j.system.2013.02.002

Hunt, K. W. (1970). Do sentences in the second language grow like those in the first? TESOL Quarterly, 4, 195-202. https://doi.org/10.2307/3585720

Li, M., \& Zhu, W. (2017). Good or bad collaborative wiki writing: Exploring links between group interactions and writing products. Journal of Second Language Writing, 35, 38-53. https://doi.org/10.1016/j.jslw.201 7.01 .003

$\mathrm{Lu}, \mathrm{X}$. (2010). Automatic analysis of syntactic complexity in second language writing. International Journal of Corpus Linguistics, 15(4), 474-496. https://doi.org/10.1075/ijcl.15.4.02lu

$\mathrm{Lu}, \mathrm{X}$. (2011). A corpus-based evaluation of syntactic complexity measures as indices of college-level ESL writers' language development. TESOL Quarterly, 45(1), 36-62. https://doi.org/10.5054/tq.2011.240859

Lu, X. (2012). The Relationship of Lexical Richness to the Quality of ESL Learners' Oral Narratives. The Modern Language Journal, 96(2), 190-208. https://doi.org/10.1111/j.1540-4781.2011.01232_1.x

Long, M. H. (1996). The role of the linguistic environment in second language acquisition. In W. C. Ritchie, \& T. K. Bhatia (Eds.), Handbook of language acquisition Second language acquisition. New York: Academic Press. https://doi.org/10.1016/B978-012589042-7/50015-3

Mozaffari, S. H. (2017). Comparing student-selected and teacher-assigned pairs on collaborative writing. Language Teaching Research, 21(4), 496-516. https://doi.org/10.1177/1362168816641703

Shehadeh, A. (2011). Effects and student perceptions of collaborative writing in L2. Journal of Second Language Writing, 20(4), 286-305. https://doi.org/10.1016/j.jslw.2011.05.010

Storch, N. (2011). Collaborative Writing in L2 Contexts: Processes, Outcomes and Future Directions'. Annual Review of Applied Linguistics, 31, 275-288. https://doi.org/10.1017/S0267190511000079

Storch, N. (2013). Collaborative writing in L2 classrooms. Multilingual Matters. https://doi.org/10.21832/978 1847699954

Vygotsky, L. S. (1978). Mind in society. The development of higher psychological processes. Cambridge, Mass: Harvard University Press.

Wigglesworth, G., \& Storch, N. (2009). Pairs versus individual writing: Effects on fluency, complexity and accuracy. Language Testing 26, 445-466. https://doi.org/10.1177/0265532209104670

Wigglesworth, G., \& Storch, N. (2012). What role for collaboration in writing and writing feedback. Journal of Second Language Writing, 21(4), 364-74. https://doi.org/10.1016/j.jslw.2012.09.005

$\mathrm{Wu}, \mathrm{H}$. (2015). The effects of blog-supported collaborative writing on writing performance, writing anxiety and perceptions of EFL college students in Taiwan. (Unpublished PhD thesis, The University of South Florida, USA).

Zhang, M. X. (2018). Collaborative writing in the EFL classroom: The effects of L1 and L2 use. System, 76, 1-12. https://doi.org/10.1016/j.system.2018.04.009

\section{Copyrights}

Copyright for this article is retained by the author(s), with first publication rights granted to the journal.

This is an open-access article distributed under the terms and conditions of the Creative Commons Attribution license (http://creativecommons.org/licenses/by/4.0/). 